\title{
DEFAULT, FORECLOSURE, AND STRATEGIC RENEGOTIATION
}

\author{
Charles KahN* \\ AND Gur HubERman†
}

I

\section{INTRODUCTION}

What determines the terms that parties include in a contract? At the most fundamental level, a contract is a reassignment of property rights. If parties voluntarily enter such a reassignment, it must be the case that the reassignment is moving property towards the party who places the higher value on it. Thus, if $A$ contracts to sell $B$ a car for $\$ 5000, A$ must value the car at no more than $\$ 5000$, and $B$ must value it at no less than $\$ 5000$. This view explains all clauses of contracts as reassigning property rights on the basis of economic efficiency: If the contract states that the purchaser of a house receives the window screens or the seller of an appliance bears the risk of malfunction for thirty days, we understand those clauses as part of an optimal reallocation. ${ }^{1}$

To be sure, the economic claim is in fact only that rights will be used by those with the highest valuation for them. A retailer contracts for the purchase of a load of clothing not because his own valuation of the goods is higher than the price, but because he anticipates the finding of further purchasers for whom the goods' value exceeds the price. Similarly, the typical purchaser of a commodity futures contract does not anticipate using the commodity himself.

Although the claim in strict form predicts only ultimate disposition of property rights, we would still expect that there is a tendency in any transaction for rights to move to the user who values them the most. For in general, establishing an exchange is an expensive procedure. Bargaining is time-consuming, and the lawyers, secretaries, and other specialized staff necessary to establish an agreement are costly. Should an agreement send goods to a party who valued the goods less than another party, further agreements will be necessary to reallocate the goods correctly. Thus, the costs of contracting are minimized by getting the allocation right in the first place.

Copyright $@ 1989$ by Law and Contemporary Problems

* Professor, Department of Economics, University of Illinois, Urbana-Champaign.

$\dagger$ Professor, Department of Economics, Tel Aviv University.

We thank Robert Marshall, David Sappington, and Helen Tauchen for their comments and suggestions. This research was supported by NSF Grant SES-8511137.

1. A. Kronman \& R. Posner, The Economics of Contract Law 1-2 (1979). 
On the other hand, when there is uncertainty, there is an opposing tendency not to get the agreement correct at the time of contracting. In any complex arrangement, many of the provisions will depend on contingencies that may arise. Normally, the buyer of a house may wish to purchase the fixtures as well; but perhaps he unexpectedly finds himself in circumstances in which it is necessary to carry out extensive interior alterations, so that the current fixtures are suddenly of no use to him. At the same time, perhaps the seller learns that his new house lacks the fixtures or perhaps he has a special attachment to some of them. When decisions are interrelated in complex ways, the correct ultimate allocation may include a complex set of contingencies. Rather than getting everything right initially, contracting parties may prefer to wait until the uncertainty is resolved and only then establish the specific bundle of rights to be transferred.

Thus, the decision as to which clauses to incorporate in a contract involves a tradeoff between increased accuracy and increased simplicity. On one hand, the contract should incorporate the array of contingent arrangements so as to make renegotiation and rewriting unnecessary. On the other hand, the contract should include only terms for those contingencies likely to arise.

According to this view, there remains a tendency for contracts to assign property rights to those for whom the property has the highest value-only now the tendency becomes a probabilistic prediction. At any round of contract formulation, the contract will tend to provide that assets be assigned to the party who will most likely have the highest valuation for them. If contingencies work out in their most likely resolutions, no further reassignment is necessary. If surprises arise, so that the allocation initially agreed upon is sub-optimal, then renegotiation occurs.

This view of renegotiation-as restoring the allocation of property to its expected optimum in the event that surprises render previously established allocations sub-optimal-lies behind many descriptions of contract formulation and renegotiation in economics. A typical example is the model of Dye, which assumes that working out contractual details is a costly procedure and consequently that contracts contain only a limited amount of detail. ${ }^{2}$ Many of the contracting models used in macroeconomics have similar assumptions behind them. ${ }^{3}$ Several models of renegotiation assume the permitted contracts are in a limited set, and as the circumstances vary, the current contract reaches a sub-optimal point at which a new choice becomes necessary. ${ }^{4}$

2. Dye, Costly Contract Contingencies, 26 INT'L Econ. Rev. 233 (1985). For other models incorporating renegotiation for remedying incompleteness of contracts, see Rogerson, Efficient Reliance and Damage Measures for Breach of Contracts, 15 RAND J. Econ. 39 (1984); Shavell, The Design of Contracts and Remedies for Breach, 99 Q. J. Econ. 121 (1984).

3. See, e.g., Gray, Wage Indexation: A Macroeconomic Approach, 2 J. Monetary Econ. 221 (1976); Taylor, Aggregate Dynamics and Staggered Contracts, 88 J. PoL. ECoN. 1 (1980).

4. Dye, Optimal Length of Labor Contracts, 26 INT'L Econ. Rev. 251 (1985); Harris \& Holmstrom, On the Duration of Agreements, 28 INT'L ECon. Rev. 389 (1987). See also Gray, On Indexation and Contract Length, 86 J. POL. ECoN. 1 (1978). 
All of these structures yield the understanding that the terms of a contract are specified to minimize future renegotiation. As a consequence, these structures predict that the terms specified in the contract are the terms most likely to be carried out in practice. There are, however, important situations that do not appear to conform to this prediction. A common example of a clause that does not conform is the provision of security for a loan.

When a bank makes a loan to a firm or home purchaser, the agreement may stipulate that the asset purchased serve as security for the loan. In other words, the bank stipulates that the asset can be seized should the borrower not repay. Nonetheless, it is expected that in the event the borrower does end up short, the loan would be renegotiated, as banks are typically less efficient managers of assets than are borrowers. It is rare for the threatened seizure of assets to take place. Why then go through the ritual of including such a provision?

In this article we show that contract terms may have purposes other than simply specifying efficient outcomes. Some clauses in a contract may be designed to place one party or the other in a strong position in the event of any renegotiation of the contract. We demonstrate that such pre-positioning can serve a useful purpose. We develop an imperfect information model in which a secured loan contract with renegotiation will achieve efficient outcomes while no other simple contract can. We use our structure to analyze and compare the efficiency of various rules for foreclosure of mortgages.

In previous articles ${ }^{5}$ we explored this use of renegotiation for strategic purposes, rather than as a remedy in the event of surprises. The distinction between the two explanations of renegotiation was highlighted by examination of situations in which there was no uncertainty (and therefore no possibility of surprise). In this article, uncertainty is integral to the model we develop; thus the renegotiation we observe is characterized by both strategy and surprise.

\section{A Model of Secured Loans}

An entrepreneur has an idea for a project that may be initiated at a cost of $K$ dollars. If this amount is greater than the entrepreneur's resources, the project will require a loan. (For simplicity, we treat the entrepreneur as having no resources of his own.) The project's value is

$$
w x y(a+1) \text {, }
$$

where the parameters are interpreted as follows: The variable $w$ is a preinvestment signal of the quality of the project. It is observed only by the entrepreneur and his bank. If (and only if) it is high enough, the project is worth undertaking. We study the contractual arrangement between the bank

5. Huberman \& Kahn, Limited Contract Enforcement and Strategic Renegotiation, 78 AM. ECON. REv. 471 (1988); G. Huberman \& C. Kahn, Strategic Renegotiation and Contractual Simplicity (July 1987) (unpublished manuscript) 
and the entrepreneur assuming that $w$ is sufficient for the investment to be desirable. By assuming that $w$ is known only to the bank and the entrepreneur, we model a situation in which the two parties enjoy a special relation, and the entrepreneur cannot replace his current lender with another. Given this justification of the special relation, the specific value of $w$ is inessential. Therefore, we may assume that $w$ is fixed and that this value is sufficiently high to justify the exclusive relation between the bank and the entrepreneur. We need not consider $w$ further.

Once the investment is made, $y$ is realized and becomes known to the entrepreneur and to the bank. Thus, we can regard $y$ as a post-investment signal of the profitability of the project. Let the distribution of $y$ be denoted $F(y)$;

$$
F(y)=0 \text { for } y<0 .
$$

The variable $a$ represents an effort level that is subsequently chosen by the entrepreneur. For concreteness, we suppose the variable takes on only one of two values: 0 or 1 . Positive effort costs the entrepreneur an amount $C$. The choice of ownership is denoted by $x: x=2$ if the entrepreneur owns the project; otherwise it is 1 .

"Ownership" deserves an explanation. In general we expect the rights to goods to be held by those who value them most. It is easy to imagine in some cases that the same good could yield different values depending on who holds it. Housing services are a natural example: One way of modeling the situation is to describe the output (housing services) as a joint product of the physical asset (housing) and particular capacities embodied in the person dwelling in the house so that the housing yields greater services when combined with one dweller than with another.

Similar effects can be had in the case of entrepreneurial investments: The outcome of the project may depend on the physical investments and the skills of the entrepreneur in charge. For example, whoever is in possession of the asset may thereby be privy to information possessed by no one else. The entrepreneur uses such information to enhance the value of the asset. People have different abilities, and, in the situation we are modeling, we assume that the original entrepreneur has more ability than anybody else. That the project is worth more if the entrepreneur owns it implies that on efficiency grounds alone, ownership should rest with the entrepreneur. ${ }^{6}$ There is a second, natural aspect to ownership of an investment project: The owner is the residual claimant of any values associated with the project.

6. The separation between ownership and control has always been a puzzle for economics. Recently, the theoretical literature has reexamined situations in which the value of assets depends on who controls decisions about their use. For papers in this vein, see Grossman \& Hart, The Costs and Benefits of Ownership: A Theory of Vertical and Lateral Integration, 94 J. PoL. Econ. 691 (1986); Hart \& Moore, Incomplete Contracts and Renegotiation, 56 Econometrica 755 (1988); Aghion \& Bolton, An "Incomplete Contract" Approach to Bankruptcy and the Financial Structure of the Firm (Mar. 1988) (unpublished working paper). 
We assume that the entrepreneur and the lender are both risk-neutral. The bank borrows or lends money at the risk-free market rate of interest. Therefore, whenever we describe the costs or benefits to the bank of future receipts or disbursements of money, we automatically translate these streams of payment into their present discounted values. The entrepreneur has limited access to the capital market. That is to say, he can lend to third parties at the risk-free rate, but if he borrows on the outside market, he will pay a premium over the amounts the bank pays to get funds from other sources. (We could justify this imperfection in the capital market on other informational grounds, but we do not pursue those possibilities here.)

This difference in ability to borrow or lend on capital markets implies that there are gains to be had by the two parties entering into some agreement. Equivalent results could be generated by using a model with risk aversion, and positing different degrees of risk aversion for the entrepreneur and the bank. Another possibility would be to start by incorporating limited liability into the analysis; the resultant behavior would be similar to that induced by differences in abilities to borrow. However, we have preferred to avoid beginning with an appeal to limited liability. Otherwise we would have to address the question of whether the need to incorporate renegotiation into contracts stemmed from the existence of limited liability itself. By using this formulation we show that it does not. As we have noted, the values of the signals $w$ and $y$ and the effort level are not known by any third party. The only variables observable by third parties are the ownership of the asset and any payments made.

It is useful to begin our analysis of this problem by examining the efficient allocation in the case of full information. The efficient allocation is characterized by the following considerations:

(1) The ownership of the asset should always be vested in the entrepreneur, since the project will have a higher value when $x=2$.

(2) The entrepreneur should invest effort in the production process whenever

$$
w \cdot 2 \cdot 2 \cdot y-C>w \cdot 2 \cdot 1 \cdot y .
$$

This inequality simply states that what the entrepreneur adds in value to the project through a high level of effort $(a=1)$ must be greater than his cost, $C$, in doing so. If not, he should not expend any effort. This inequality may be rewritten as

$$
y>C /(2 w) \text {. }
$$

(3) Payments made by the entrepreneur to the bank should never be greater than

$$
w \cdot 2 \cdot y(a+1)-C a,
$$

which is the net benefit of the project in a realization.

(4) Finally, the project should be undertaken initially if, and only if, the expectation of the net benefit of the project is greater than $K$ :

$$
\int \max (2 w y, 4 w y-C) d F(y)>K \text {. }
$$




\section{III}

\section{Contracts}

Next we consider various contracts that could be offered in this environment. Recall that contracts cannot directly depend on realizations of $y, w$, or $a$, since these variables are not observed by outside parties.

The simplest contract merely specifies who owns the project and what monetary payment, if any, is to be made. The next simplest contract is one that gives one party the option to transfer the ownership to the other for a specified price. Such contracts can take many forms. For example, contracting parties frequently treat the good as security for the loan: At his option, the borrower either pays the specified repayment of the loan or gives up the security to the lender. We will concentrate on this form of the contract. We will examine the security contract that gives zero expected profits to the lender. (To justify concentrating on the zero-profits contract, assume that at the outset there are a large number of banks, each potentially possessing the ability to enter the special relationship with the entrepreneur, and therefore competing away their expected profits from the arrangement.)

To evaluate contracts in the presence of possible renegotiation requires a theory of the outcomes of negotiations. We assume that negotiations work as follows: If parties are already committed to an outcome that is Pareto optimal, then there is no further negotiation. If, however, previously signed contracts commit the parties to an inefficent outcome such that both sides could gain from a renegotiation, then further negotiation will occur. We assume that the outcome that the parties reach as a result of the renegotiation is an efficient outcome in which the gains from the move are split evenly. ${ }^{7}$

In the case of a contract in which one party has the right to exercise an option, renegotiation works as follows: If the party owning the option prefers the alternative that is Pareto optimal, no renegotiation occurs, and the party carries out his preferred alternative. Suppose on the other hand that the party owning the option personally prefers the alternative that is Pareto inferiorthat is, the other party is willing to offer a side payment large enough to induce the party owning the option to switch away from his preferred alternative. In this case, renegotiation will occur. The assumption of equal division of the gains determines the size of the resultant side payment.

We consider the following secured loan arrangement: The entrepreneur agrees to repay $T$ to the lender. If the entrepreneur fails to repay, then the lender receives the assets in the project.

7. Given the risk neutrality of both parties, this assumption implies the choice of the Nash bargaining solution.

The literature on bargaining and predicted outcomes of bargaining is voluminous. An important non-cooperative model is Rubinstein, Perfect Equilibrium in a Bargaining Model, 50 EconomETriCA 97 (1982). For cooperative game theoretical approaches, of which equal division and Nash bargaining solutions are notable examples, see R. Luce \& H. Raiffa, Games and Decisions: Introduction and Critical Survey (1958). 
How does such an agreement work in the presence of renegotiation? Consider the point at which the entrepreneur has the option of handing over the asset or of paying up. If the value of the asset to the entrepreneur is greater than $T$, he prefers to pay and retain the asset. If the value of the asset is less than $T$, he prefers to threaten to hand over the asset to the bank. Given this threat, which is credible unless the contract is renegotiated, the bank prefers to renegotiate the initial loan.

The value to the bank of the unrenegotiated loan is

$$
\text { wy }(a+1) \text {, }
$$

which is equal to the value of the project when $x=1$ (since the entrepreneur no longer owns the project). The value to the entrepreneur of the unrenegotiated loan is $-a C$, which represents his costs in terms of the effort he put into the project. The social value of leaving the asset in the entrepreneur's hands is

$$
2 w y(a+1)-a C \text {. }
$$

According to our bargaining theory, each party will receive half of the difference of the gain from leaving the project in the entrepreneur's hands; thus the total payment by the entrepreneur to the bank is

$$
1.5 w y(a+1) \text {. }
$$

The net benefit to the entrepreneur is

$$
\max (.5 w y(a+1)-a C, 2 w y(a+1)-a C-T),
$$

and the net benefit to the bank is

$$
\min (1.5 \cdot w y(a+1), T) .
$$

Next we consider the entrepreneur's decisions regarding the effort he will expend under a secured loan contract, given his awareness of the outcomes of the subsequent bargaining as described above. The entrepreneur prefers to choose $a=1$ if and only if, $y$ is above some critical level. He chooses $a$ to solve the following problem:

$$
\max (\max \{(.5 w y(a+1)-a C),(2 w y(a+1)-a C-T)\})
$$

The first value in the brackets represents his income from a renegotiated project; the second represents income where no renegotiation takes place. The entrepreneur will choose $a$ to maximize the larger of the two values. Straightforward calculation demonstrates that it is optimal to set $a$ equal to zero if

$$
(1.5 w y>T \text { and } 2 w y>4 w y-C) \text {, }
$$

or if

$$
(1.5 w y<T<3 w y \text { and } .5 w y>4 w y-T-C) \text {, }
$$

or if

$$
(3 w y<T \text { and } .5 w y>w y-C) \text {. }
$$

Otherwise, it is optimal to set $a$ equal to one.

Thus, if 
$a$ is chosen efficiently.

Provided (1) holds, $T$ is defined by the requirement that the lender make zero expected profits. In other words,

$$
\int \min (1.5 w y, T) d F(y)=K \text {. }
$$

(This simplified version of the profits formula is valid because when (1) holds, the entrepreneur chooses $a$ equal to zero whenever $T$ exceeds the project's value.) Note that $T$ is therefore greater than $K$, the difference representing the default premium. Thus provided

$$
\int \min (1.5 w y, .75 C) d F(y)>K,
$$

the efficient solution is generated by this security contract. It can be verified that in these cases the value of the project does indeed exceed the cost of it.

Next we consider alternative simple contracts and demonstrate that none of these alternatives would be successful.

(1) The simplest contract would be one that requires the debtor unconditionally to pay the creditor an amount $K$. In effect we could describe such a contract as holding the debtor personally liable for the debt. In this context, we could interpret such liability as courtenforced repayment even in circumstances where the debtor must obtain funds beyond those generated by the project. (Imagine, for example, a garnishment of wages in another job.) Such a requirement would be complicated by the costs of enforcing the contract if the debtor attempts to default. We will consider the complications of court costs below; for now, however, note that even if the enforcement costs were zero, this contract would not be as desirable as the security contract because it would inefficiently allocate the risk of repayment. Note the following related undesirable effect of such a contract: It would, for certain values of $y$, cause over-investment in effort as the debtor attempted to avoid being required to obtain outside funds to repay his debts.

(2) A second possibility would be for the bank to own the project and, at its discretion, hand the project over to the entrepreneur for a consideration. This possibility would also be inefficient relative to the security contract: Since the bank will share in the gains made as a result of the investment by the entrepreneur, the entrepreneur will tend to under-invest in effort. ${ }^{8}$

(3) In a world that prohibited renegotiation, no simple contract would be efficient. If a contract specified that in some circumstances the asset were to end up in the wrong hands, it would be inefficient. But the only alternative for an unrenegotiated contract is one in

8. This is a specific example of the "hold-up problem." For the development of firms as a response to the hold-up problem, see O. Williamson, The Economic Institutions of Capitalism: Firms, Markets, Relational Contracting (1985); Klein, Crawford \& Alchian, Vertical Integration, Appropriable Rents, and the Competitive Contracting Process, 21 J. L. Econ. 297 (1978). 
which the asset remains in the same hands in all realizations. In this case, the only incentive-compatible contract is one in which the payment does not vary with the realization of $y$.

In summary: We have established a simple economic structure in which a security contract with renegotiation dominates any other simple contract. The security contract allows the payment from the entrepreneur to the bank to vary in a flexible way, depending on the realization of the outcome of the project, even though this amount is not stated in the contract and cannot be stated effectively since it is not observable by any third party.

This flexibility makes renegotiation a useful tool, but does not by itself explain the usefulness of security contracts. The security contract dominates other contracts because it places the asset in the proper party's hands, depending on the realization of the outcome of the project. Because the owner gets residual claims to the benefits of the asset, we want the ownership of the asset to be in the hands of the entrepreneur in any state in which it is worthwhile for him to make additional effort investments. On the other hand, we want the asset in the hands of the bank in low productivity states-that is, those states in which additional effort is not useful-in order to enable the bank to obtain some value from the project through bargaining in those states. We do not want the bank to have the right to personal liability of the entrepreneur for the debt, since that right would eliminate the proper risksharing in the agreement.

\section{IV}

\section{Rules and Costs OF ENForcement}

Thus far, we have made extremely simple assumptions about the enforcement of the right of the lender to take over the asset in the case of default. We have assumed that in the event of a default, the banker can appropriate the project without cost and at his own discretion. It is this threat which gives him residual bargaining power in the renegotiation.

This procedure comes closest to describing the most primitive version of foreclosure, namely strict foreclosure. In the United States, strict foreclosure remains permissible in only a handful of states. In most states it has been supplanted by judicial foreclosure. Under classical judicial foreclosure, the assets of the defaulting borrower are taken over and sold by the court. If their value exceeds the amount of the debt, the balance is given to the debtor. If their value is less than the amount of the debt, then a deficiency judgment may be rendered, in appropriate circumstances, against the debtor for the balance. The court's actions provide procedural safeguards for the debtor and are generally more costly than a direct takeover of the assets by the creditor. ${ }^{9}$

In response to the rise in judicial foreclosure, parties to contracts resorted to including terms for foreclosure as part of their contracts. In some respects, this non-judicial foreclosure is a return to the older terms of strict foreclosure.

9. P. Goldstein, Real Property 443 (1984). 
In this section we will compare the effectiveness of strict and judicial foreclosure in determining whether secured loan contracts can lead to efficient outcomes. To the model of the previous section we add one simple assumption: The costs of a court-administered foreclosure are a constant $p$.

\section{A. Case I: Court Protection of Debtors}

Imagine that the court enforces a rule that the lender can recover an amount no greater than the face value of the debt (plus court costs); any excess value will be returned to the borrower. (This rule is often enforced by judicially-held public auction of the property.) How will such a rule affect the efficiency of secured loans?

As long as the value of the asset to the entrepreneur is greater than the value to any third-party buyer, the value of the asset when sold will never exceed the value to the entrepreneur. Thus the main effect of the new rule arises through the imposition of extra court costs. In the case of default, the new rule implies that the bank will receive a reduced value from the assets:

$$
w y(a+1)-p
$$

The net social gain from avoiding a default and leaving the asset in the entrepreneur's hands is therefore

$$
w y(a+1)+p
$$

-that is to say, the avoidance of court costs becomes an extra gain in renegotiating away from default. The gain is split evenly between the parties, so that the entrepreneur now receives

$$
\text { (2) } \max \{.5 w y(a+1)+.5 p-a C, 2 w y(a+1)-a C-T\}
$$

and the bank receives

$$
\min \{1.5 w y(a+1)-.5 p, T\} .
$$

How does this change affect the entrepreneur's incentives to invest? The entrepreneur picks $a$ to maximize (2); calculations analogous to those in the previous section show that the entrepreneur will pick the efficient level of effort provided

$$
.75 C>T+.5 p .
$$

To clarify, note that the entrepreneur's objective function here is the same as his objective function in the previous section, with $T+.5 p$ substituted for $T$. Furthermore, the efficient choice of $a$ is independent of the cost $p$, provided that renegotiation will allow the avoidance of court appearances.

The zero-profits level of $T$ is defined by the expression

$$
\int \min \{1.5 w y-.5 p, T\} d F(y)=K,
$$

so that efficient outcomes are achievable with the secured loan contract, provided that

$$
\int \mathrm{p} \min (1.5 w y, .75 C) d F(y)>K+.5 p .
$$

Note, therefore, that the presence of court costs decreases the likelihood of achieving the efficient outcome with a secured loan contract, even though 
the court is never actually used-that is to say, even though in practice the parties always renegotiate rather than submit to judicial foreclosure. The court costs become important because they impose an extra burden on the lender, reducing his power in any renegotiation away from an inefficient outcome.

\section{B. Case II: Court Protection of Creditors}

Now imagine that the court enforces deficiency judgments: If the value of the asset falls short of the debt, the court will assess the debtor for the balance. In contrast to the previous case, deficiency judgments in this case destroy the usefulness of the secured loan contract entirely-even if the debtor is not assessed court costs.

For example, consider the debtor's choices of whether or not to default in a regime with deficiency judgments. If the debtor wishes to avoid foreclosure and the asset is not worth the value of the indebtedness, then the debtor will have to obtain costly funds. However, if the debtor does default, because the asset is worth less on the open market than it is to the debtor, the debtor will be forced to obtain even a greater amount of costly funds. Thus the debtor never threatens bankruptcy, and contracts are never renegotiated. In effect, a regime with deficiency judgments is equivalent to a regime in which renegotiation is prohibited. ${ }^{10}$

\section{$\mathrm{V}$ \\ Remaining Issues: Non-Judicial Foreclosure}

Given the restrictions inherent in the process of judicial foreclosure, it is not surprising that the procedure has largely been supplanted by non-judicial foreclosure-the inclusion of terms in the loan contract specifying the circumstances and procedures by which the lender will obtain assets from the borrower in the event of default. Non-judicial foreclosure is in effect a form of liquidated damages, a statement by the parties as to the remedies to be applied in the event of breach of the contract. Although it is not surprising that non-judicial foreclosure would be preferred to a court-mandated foreclosure procedure, it is perhaps surprising to learn which of the aspects of judicial foreclosure are the most disadvantageous. Our preceding analysis indicates that it is the use of deficiency judgments even more than the costliness of the litigation itself that leads to the avoidance of judicial foreclosure.

If this conclusion is correct, it implies two interesting classes of predictions. The first involves the terms of observed contracts. Our

10. This result is complicated by the fact that deficiency judgments themselves may not always be effective. Despite receiving the judgment, the creditor may not collect if, for example, the debtor declares bankruptcy or skips town. If the creditor predicts that a deficiency judgment will not actually result in any payment, then the problem reduces itself to that of the previous section. To the extent that deficiency judgments are successful, they neutralize the value of foreclosure as an element in strategic renegotiation. 
description of secured-loan contracts predicts a tendency for such contracts to specify that, in the event of default, the debtor's liability will be limited to the surrender of the secured property. ${ }^{11}$

The second class of predictions involves legislative responses to and interpretations of secured-loan contracts. In particular, several states have instituted various forms of legislation to limit deficiency judgments. ${ }^{12}$ While these actions can be understood simply as sympathetic responses to debtors' plights, our analysis shows that they can also be interpreted as guaranteeing that mortgages act as limited liability instruments and consequently that this form of secured loan yields the advantages we have described in this paper.

Finally, this analysis is of relevance to the question of revision of contractual duty in contract law. When a lender agrees to a reduction in the payment required, in what sense is this renegotiated agreement an enforceable contract? Can the lender subsequently demand the original amounts based on the pre-existing duty rule? In the case of "matured and liquidated" money debts, courts have had to find a modification of the terms of the payment-even in the most minute detail of location of payment or person to be paid-to serve as the consideration for the revised contract. ${ }^{13}$ In the absence of strategic considerations, there would be no economic justification for allowing the revision of a liquidated money debt: One party's loss would be the other's gain, and the foreknowledge of the possibility of being held up would reduce parties' willingness to enter into contracts. ${ }^{14}$ Our analysis shows that revisions of money debts can serve a socially useful purpose. It also suggests that in the case of secured loans, we should treat the borrower's decision to forego default as the consideration in the revised contract.

11. There is a major limitation to the applicability of this prediction: In the case of multiple lenders to a single firm, secured loans will be used to make favored lenders more senior in the event of bankruptcy. The interpretation of secured loans in such circumstances requires a much more complex analysis. Investigations in which the competition among creditors constitutes the center of a bankrupty analysis are Baird, The Uneasy Case for Corporate Reorganizations, 15 J. LeGal STUD. 127 (1986); Jackson, Translating Assets and Liabilities to the Bankruptcy Forum, 14 J. Lecal STud. 73 (1985). For a formal economic analysis explicitly based on the inability of certain classes of creditors to renegotiate (because of the transaction costs involved in getting together), see White, Public Policy Toward Bankruptcy: Me-First and Other Priority Rules, 11 BELL J. ECoN. 550 (1980).

12. Goldstein outlines some of the responses. Some states, such as California, have instituted legislation prohibiting deficiency judgments outright in certain circumstances and limiting the sums obtainable in other circumstances. Since this rule could be evaded by a mortgagee who took action first against the mortgagor personally and only subsequently against the property for the balance of the amount due, some states have enacted "one-action" rules, which require the mortgagee to proceed against the property first, effectively limiting him to only one remedy. P. GoLdstein, supra note 9 , at $444-45$. 1982).

13. J. Dawson, W. Harvey \& S. Henderson, Contracts, Cases and Comments 523 (4th ed.

14. Dawson, Harvey, and Henderson suggest that even "unforeseen circumstances" do not serve as a solid theoretical justification for making exceptions to the rule of pre-existing duty. Id. at 537. 


\section{Conclusion}

This article has developed a simple economic setting in which security contracts with renegotiation dominate other simple contacts. These contracts encourage the borrower to make proper investments in successful projects, while allowing the lender to recapture some of the value of unsuccessful projects through renegotiation of the loan under a threat of foreclosure.

This setting emphasizes a strategic approach to renegotiation. The standard economic approach predicts that property rights will be assigned to those parties predicted to have the highest valuation of them. Renegotiation is, therefore, a technique for reallocating property in an efficient manner after unexpected occurrences have rendered an initial allocation sub-optimal.

In contrast, our approach emphasizes that property rights may be assigned initially on a strategic basis. In some circumstances it is desirable to assign property not to the party who has the greatest ultimate use for the property, but to the party who should be endowed with bargaining power in subsequent periods. While a lender typically has less use for the secured property than does a borrower, a security contract assigns the property right to the lender in case of default in order to give the lender the power to extract as much value as possible when default occurs.

The model has demonstrated that this arrangement can yield financing for useful projects that would remain unfinanced under alternate arrangements. This article has also briefly examined the consequences that arise from variations in the rules for enforcing the provisions of secured loans. We have shown that increasing the costliness of the foreclosure procedure reduces the usefulness of the secured loan even if no loans ever proceed through foreclosure: The added costs reduce the bargaining position of the creditor when default occurs. This article has shown that automatic court protection of creditors eliminates the usefulness of security by making it impossible for creditor and debtor to share risks in an efficient manner.

Thus, a novel feature of our framework is that it makes possible a comparison of the effectiveness of various legal regimes for handling default and foreclosure. Future work will give a more detailed examination of the variation in foreclosure laws in various jurisdictions and the effects on the loan market. 
